\title{
Synthesis and Photostability Study of Some Modified Poly(vinyl chloride) Containing Pendant Benzothiazole and Benzimidozole Ring
}

\author{
Emad Yousif \& Ayad Hameed \\ Department of Chemistry, College of Science \\ AL-Nahrain University, Baghdad, Iraq \\ E-mail: emad_yousif@hotmail.com \\ Rashed Rasheed \& Hadeel Mansoor \\ Applied Chemistry Division, Department of Applied Sciences \\ University of Technology, Baghdad, Iraq \\ Yang Farina, Abdualbasit Graisa, Nadia Salih \& Jumat Salimon \\ School of Chemical Science \& Food Technology \\ University Kebangsaan Malaysia, Malaysia
}

\begin{abstract}
The influence of introducing benzothiazole and benzimidazole as a pending groups into the repeating unit of PVC has been studied on the bases of photostability measurements. The photostability of modified polymers were studied by monitoring the carbonyl Index $\left(\mathrm{I}_{\mathrm{CO}}\right)$, polyene index $\left(\mathrm{I}_{\mathrm{po}}\right)$ and hydroxyl index $\left(\mathrm{I}_{\mathrm{OH}}\right)$, all results obtained indicated that PAA, PSS, PNN, PSA and PNA gave lower growth rate of $\mathrm{I}_{\mathrm{CO}}$, $\mathrm{I}_{\mathrm{PO}}$ and $\mathrm{I}_{\mathrm{OH}}$ with irradiation time with respect to unmodified PVC film (control). The following trends of photostability are obtained

\section{$\mathrm{PAA}>\mathrm{PSS}>\mathrm{PNN}>\mathrm{PSA}>\mathrm{PNA}$}

According to the experimental results several reaction mechanisms were proposed depending on the presence of benzothiazole and benzimidazole moieties in the polymer chain. The mode of chain scission was also investigated by measuring the variation of average viscosity molecular weight with irradiation time for modified PVC. The degree of deterioration $(\alpha)$ and the average number of chain scission $(\mathrm{S})$ values were also calculated.
\end{abstract}

Keywords: PVC, UV-light, Heterocyclic

\section{Introduction}

Synthesis of polymer-bound chelating ligands and the selective chelation of specific metal ions is a field of active research (Pittmann 1980). A number of ligands including polydentate amines, crown ethers, phosphines, bipyridines, and naphthyridines have been bound with mainly polystyrene divinylbenzene copolymers (Jellinek 1978 \& Gardette et al. 1993). These studies are mostly concerned with ion-binding and catalytic aspects. Very little information appears to exist as to whether (Andrady et al. 1998), and to what extent, such polymer modifaction can influence the properties of the macromolecule (Aliwi et al. 2005). Recently, scientists does able to modified (Yousif et al. 2007) PVC by introduction aromatic and heterocyclic moieties through halogen displacement reaction. PVC, thus modified, showed improved overall photochemical stability. The facial chlorine displacement from PVC indicated the possibility on easy anchoring of ligands to PVC matrix. In view of paucity of any information on PVC in this line, we undertook the synthesis of PVC-heterocyclic compounds.. This article will describe the synthetic procedure adopted (Scheme 1) and the photostability of these new polymers towards UV light.

\section{Materials and methods}

\subsection{Preparation of modified polymers}

\subsubsection{Preparation of modified polymer (PAA)}

2-amino benzothiazole ( $1.67 \mathrm{mmole})$ was added to $(0.125 \mathrm{~g})$ poly (vinyl chloride) and three drops of pyridine in $(25 \mathrm{~mL})$ tetrahydrofuran (THF) was also added. A white prcipitate was formed after refluxing the mixture for three hours the modified polymer (PAA) was filtered,washed with redistilled water, ethanol, ether and dried under vacuum. 


\subsubsection{Preparation of modified polymer (PSS)}

2- mercapto benzothiazole ( $1.49 \mathrm{mmole})$ was added to $(0.125 \mathrm{~g})$ poly(vinyl chloride) and three drops of pyridine in $(25$ $\mathrm{mL}$ ) tetrahydrofuran (THF) was also added. A yellow prcipitate was formed after refluxing the mixture for three hours, the modified polymer (PSS) was filtered,washed with redistilled water, ethanol, ether and dried under vacuum.

\subsubsection{Preparation of modified polymer (PNN)}

2-Amino benzimidazole $(1.87 \mathrm{mmole})$ was added to $(0.125 \mathrm{~g})$ poly(vinyl chloride) and three drops of pyridine in $(25$ $\mathrm{mL}$ ) tetrahydrofuran (THF). A brown prcipitat was formed after refluxing the mixture for three hours the modified polymer (PNN) was filtered, washed with redistilled water, ethanol, ether and dried under vacuum.

\subsubsection{Preparation of modified polymer (PSA)}

A solution of mixture of $(0.83 \mathrm{mmole}) 2$-amino benzothiazole and $(0.75 \mathrm{mmole})$ of 2-mercapto benzothiazole and three drops of pyridine in $(25 \mathrm{~mL})$ tetrahydrofuran (THF) was added to $(0.125 \mathrm{~g})$ poly(vinyl chloride). A brown prcipitat was formed after refluxing the mixture for three hours, the modified polymer (PSA) was filtered, washed with redistilled water, ethanol, ether and dried under vacuum.

\subsubsection{Preparation of modified polymer (PNA)}

A solution of mixture of $(0.94 \mathrm{mmole}) 2$-amino benzimidazole and $(0.83 \mathrm{mmole}) 2$-amino benzothiazol and three drops of pyridine in $(25 \mathrm{~mL})$ tetrahydrofuran (THF) was added to $(0.125 \mathrm{~g})$ poly(vinyl chloride). A brown precipitate was formed after refluxing the mixture for three hours, the modified polymer (PNA) was filtered, washed with redistilled water, than ethanol, ether and dried under vacuum. The physical properties of prepared modified polymers are listed in Table (1)

\subsection{Photodegradation measuring methods}

\subsubsection{Films Preparation}

Asolution of Poly(vinyl chloride) solution or modified Poly(vinyl chloride) $(5 \mathrm{~g} / 100 \mathrm{ml})$ in tetrahydrofuran (THF) was used to prepare $(30 \mu \mathrm{m})$ thickness of polymer films, (measured by a micrometer type $2610 \mathrm{~A}$, Germany). The films were prepared by evaporation technique at room temperature for 24 hours. To remove the possible residual tetrahydrofuran solvent, film samples were further dried at room temperature for three hours under reduced pressure.

\subsubsection{Accelerated testing technique}

Accelerated weatherometer Q.U.V. tester (Q. panel, company, U S A), was used for irradiation of polymers films. The accelerated weathering tester contains stainless steel plate, which has two holes in the front side and a third one behind. Each side contains a lamp (type Fluorescent Ultraviolet Lights) 40 Watt each. These lamps are of the type UV-B 313 giving spectrum range between $290-360 \mathrm{~nm}$ with a maximum at wavelength $313 \mathrm{~nm}$. The polymer film samples were vertically fixed parallel to the lamps to make sure that UV incident radiation is perpendicular on the samples. The irradiated samples are rotated from time to time to ensure that the intensity of light incident on all samples is the same.

\subsubsection{Photodegradation measuring methods}

\section{A. Measuring the photodegradation rate of polymer films using infrared spectrophotometery}

The degree of photodegradation of polymer film samples was followed by monitoring FTIR spectra in the range 4000$400 \mathrm{~cm}^{-1}$ using FTIR 8300 Shimadzu Spectrophotometer. The position of carbonyl absorption is specified at $1722 \mathrm{~cm}^{-1}$, polyene group at $\left(1602 \mathrm{~cm}^{-1}\right)$ and the hydroxyl group at $3500 \mathrm{~cm}^{-1}$. The progress of photodegradation during different irradiation times was followed by observing the changes in carbonyl and polyene peaks. Then carbonyl $\left(\mathrm{I}_{\mathrm{co}}\right)$, polyene $\left(\mathrm{I}_{\mathrm{po}}\right)$ and hydroxyl $\left(\mathrm{I}_{\mathrm{OH}}\right)$ indices were calculated by comparison of the FTIR absorption peak at 1722, 1602 and $3500 \mathrm{~cm}^{-}$ ${ }^{1}$ with reference peak at $1328 \mathrm{~cm}^{-1}$, respectively. This method is called band index method which includes (Rabek \& Ranby 1975):

$$
\text { Is }=\frac{\mathrm{As}}{\mathrm{Ar}}
$$

As $=$ Absorbance of peak under study.

$\mathrm{Ar}=$ Absorbance of reference peak.

Is = Index of group under study.

Actual absorbance, the difference between the absorbance of top peak and base line (A Top Peak - A Base Line) is calculated using the Base Line method (Rabek \& Ranby 1975).

B. Determination of average molecular weight $\left(\overline{\mathrm{M}}_{\mathrm{v}}\right)$ using viscometry method: 
The viscosity property was used to determine the average molecular weight of polymer, using the Mark- Houwink relation (Mark 2007).

$$
[\eta]=K \bar{M}_{\mathrm{v}}^{\alpha}
$$

$[\eta]=$ the intrinsic viscosity.

$\mathrm{K}, \alpha=$ are constants depend upon the polymer-solvent system at a particular temperature.

The intrinsic viscosity of a polymer solution was measured with an Ostwald U-tube viscometer. Solutions were made by dissolving the polymer in a solvent $(\mathrm{gm} / 100 \mathrm{ml})$ and the flow times of polymer solution and pure solvent are $\mathrm{t}$ and to respectively. Specific viscosity $\left(\eta_{\mathrm{sp}}\right)$ was calculated as follows:

$$
\eta_{\mathrm{re}}=\frac{\mathrm{t}}{\mathrm{t}_{\mathrm{o}}}
$$

$\eta_{\mathrm{re}}=$ Relative viscosity

$$
\eta_{\mathrm{sp}}=\eta_{\mathrm{re}}-1
$$

The single - point measurements were converted to intrinsic viscosities by the relation 2 .

$$
[\eta]=(\sqrt{2} / \mathrm{c})\left(\eta_{\mathrm{sp}}-\ln \eta_{\mathrm{re}}\right)^{1 / 2}
$$

$\mathrm{C}=$ Concentration of polymer solution $(\mathrm{g} / 100 \mathrm{ml})$.

By applying equation 5, the molecular weight of degraded and un-degraded polymer can be calculated.Molecular weights of PVC with and without additives were calculated from intrinsic viscosities measured in THF solution using the following equation;

$$
[\eta]==1.38 \times 10^{-4} \mathrm{Mv}^{0.77}
$$

The quantum yield of main chain scission $\left(\phi_{\mathrm{cs}}\right)$ (Nakajima et al. 1990) was calculated from viscosity measurement using the following relation (7).

$$
\phi_{\mathrm{cs}}=\left(\mathrm{CA} / \overline{\mathrm{M}}_{\mathrm{v}, \mathrm{o}}\right)\left[\left(\left[\eta_{\mathrm{o}}\right] /[\eta]\right)^{1 / \alpha}-1\right] / \mathrm{I}_{\mathrm{o}} \mathrm{t}
$$

Where: $\mathrm{C}=$ concentration; $\mathrm{A}=$ Avogadro's number; $\left(\overline{\mathrm{M}}_{\mathrm{v}, \mathrm{o}}\right)=$ the initial viscosity-average molecular weight; $\left[\eta_{\mathrm{o}}\right]=$ Intrinsic viscosity of PVC polymer before irradiation; $\mathrm{I}_{\mathrm{o}}=$ Incident intensity and $\mathrm{t}=$ Irradiation time in second.

\section{Results and Discussion}

\subsection{Synthesis of PVC bound benzothiazole and benzimidazole ring system}

Polymers with an aromatic and heterocyclic rings have been drawing the attention of researchers more due to their importance in many aspects of interest, among these polymers are modified poly(vinyl chloride). PVC are modified by introducing aromatic and heterocyclic moieties through halogen displacement reaction mainly by $\mathrm{S}_{\mathrm{N} 2}$ mechanism, modified PVC polymers have developed over the past decade into a fast growing industrial application field. They have also attracted attention because of their importance as catenation ligands. Also, the thermal stabilities of (PVCaromatic). Polymers are comparable better than unmodified PVC. In addition, most of them showed improved changes in electro physical properties, especially in dielectric properties. In continuation of our earlier studies on the synthesis of modified PVC, we undertook in this research the synthesis of some new modified PVC containing heterocyclic systems viz., benzothiazole and benzimidazole (polymers prepared), with a view to finding out the effect of introducing these moieties on physical and chemical properties of PVC. The reaction was initiated by the nucleophilic attack of (S,N) atoms on the carbon carrying chlorine atom in the polymeric chain followed by departure of chloride anion as a good leaving group. 


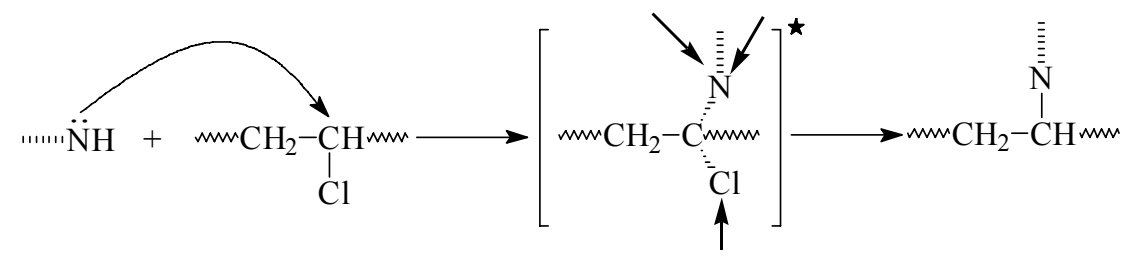

\subsection{Characterization of modiefied polymers}

\subsubsection{Infra-red Spectroscopy}

The structure of the present polymers was confirmed by Infra-red spectroscopy. The most common bands are tabulated in Table (2), beside the typical I R absorption bands, each of the present polymers showed other band characteristic of its own structure, Polymers showed the following features, a medium to strong band at about $(630) \mathrm{cm}^{-1}$ which could be attributed to $(\mathrm{C}-\mathrm{Cl})$, the appearance of a medium band at about $(1550) \mathrm{cm}^{-1}$ indicated that the end groups of these polymers are $\mathrm{C}=\mathrm{C}$ double band, the bands at around $(2900) \mathrm{cm}^{-1}$ which was assigned to the typical aliphatic $(\mathrm{C}-\mathrm{H})$ stretching vibration was also observed, moreover, these polymers exhibited significant bands in the region at (3050 for $v$ ( $\mathrm{C}-\mathrm{H}$ aromatic), 1635 for $v(\mathrm{C}=\mathrm{N})$ and at 750 for $(\mathrm{C}-\mathrm{H}$ bending of $O$-disubstituted benzene) that clearly indicated the presence of the benzothiazole and benzimidazole nucleus in the backbone of PVC chain.

\subsubsection{Ultraviolet-visible Spectroscopy}

The ultraviolet-visible spectrophotometry technique is used to characterize the polymers in tetrahydrofuran (THF) as a solvent. The ultraviolet visible electronic spectra of the modified polymers, showed an absorption bands could be attributed to the $\pi \rightarrow \pi^{*}$ electronic transitions, These transitions are assigned in relevance to the structures of polymers. As shown in Table (3). The increase of the absorbance in the uv-vis range for samples containing modified PVC can be explaned by the formation of conjugation double bonds (band corresponding to the $\pi \rightarrow \pi^{*}$ transition ) in these modified polymers resulting from introducing an aromatic benzothiazole and benzimidazole rings. Thus, shifting the absorbance to longer wavelengths (i.e the bathochromic effect ) is good evidence that modification were formed in our PVC. Moreover, the broadness in the bands caused by the presence of other chromophores such as $(\mathrm{C}=\mathrm{N}$, etc) which absorb in the above region and this overlapping bands make the interpretation of the results difficult.

\subsection{Photostabilization of modified PVC film}

The new modified polymers PAA, PSS, PNN, PSA and PNA. were used as photostablized modified PVC comparing with PVC films(control).In order to study the photochemical activity of these modified polymers for the photostabilization of films, the carbonyl, polyene and hydroxyl indices were monitored with irradiation time using IR spectroscopy. The formation of carbonyl group $(\mathrm{C}=\mathrm{O})$ and polyene $(\mathrm{C}=\mathrm{C})_{\mathrm{n}}$ and $(\mathrm{O}-\mathrm{H})$ during photolysis of PVC film could be illustrated by the following mechanism.

When PVC is photolysed in the presence of $\left(\mathrm{O}_{2}\right)$, the primary photochemical processes occur (the excited singlet polyenes).

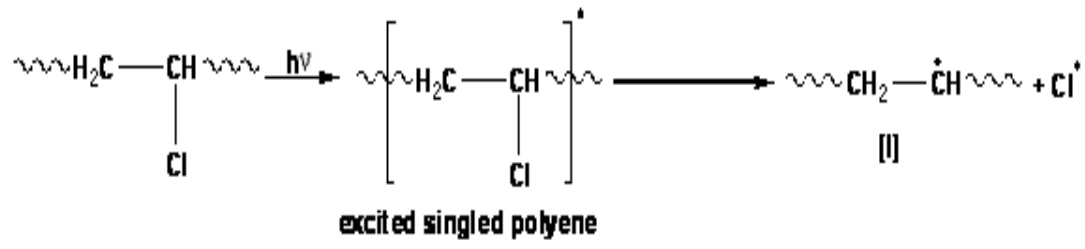

Those excited states will thus disappear by the different routes including the allylic $(\mathrm{C}-\mathrm{Cl})$ bond cleavage with formation of $(\mathrm{Cl})$ radical and polyene radical[I]. The polyenyl radical [I] which bears no $(\mathrm{Cl})$ atom in the $\alpha$-position is very likely to be scavenged by $\left(\mathrm{O}_{2}\right)$ to give peroxy radical [II]

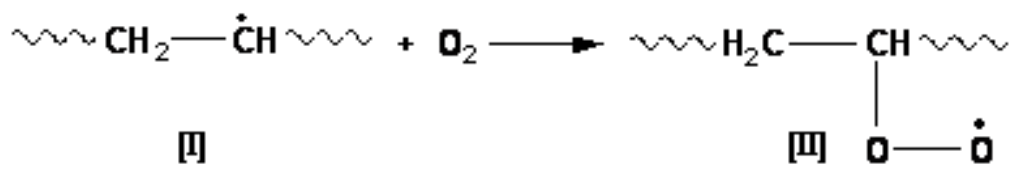

Rate constant measurement on related model compounds suggest that peroxy radical [II] react with the $\left(-\mathrm{CH}_{2}-\right)$ and (CH-Cl) groups on PVC at rates that are comparable. The attack on $\left(\mathrm{CH}_{2}\right)$ group yields radical [III]. 


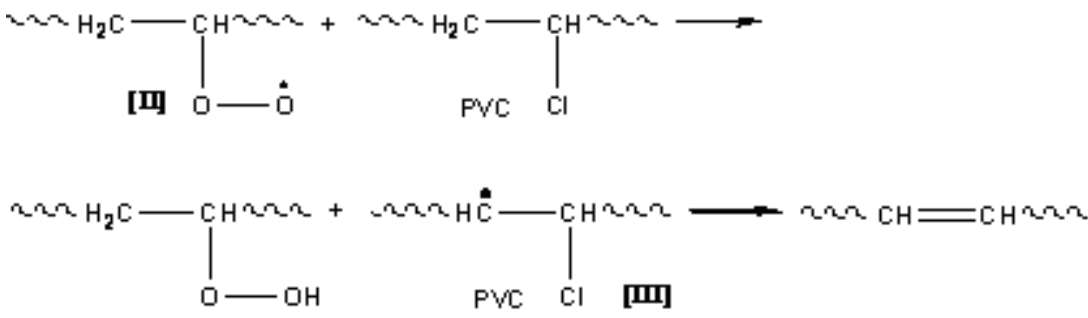

This radical contributes to the chain-dehydrochlorination of PVC. The attack of II on the (-CH-Cl) group yield radical [IV] which possesses no labile $\beta$-chlorine and is likely to react with $\left(\mathrm{O}_{2}\right)$ to give a $\gamma$-chloroalkyl peroxy radical [V].

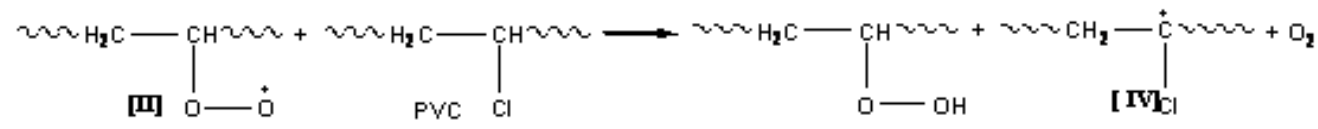<smiles>CCCCCC(C)(Cl)O[O]</smiles>

The main oxidation products of PVC are expected to result primary from the various reactions of this radical [V], there are two major routes of the fate (disappearances) of the $\gamma$-chloroalkyl peroxy radical. The hydrogen abstraction from PVC with the formation of hydroperoxide groups.

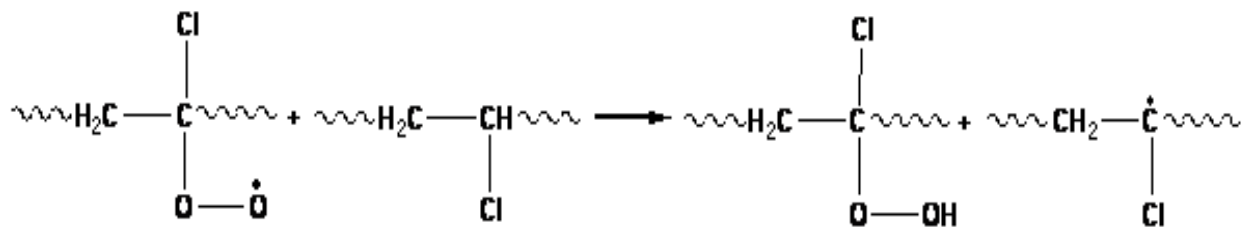

The bimolecular interaction, the later leads to the formation of either a peroxide bridge (termination reaction),

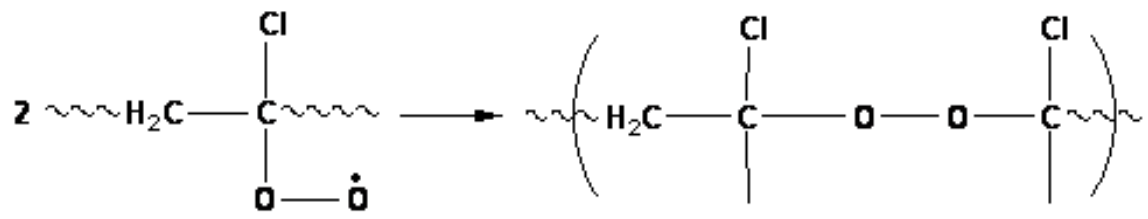

peroxide bridge

the formation of alkoxy radicals[VI].

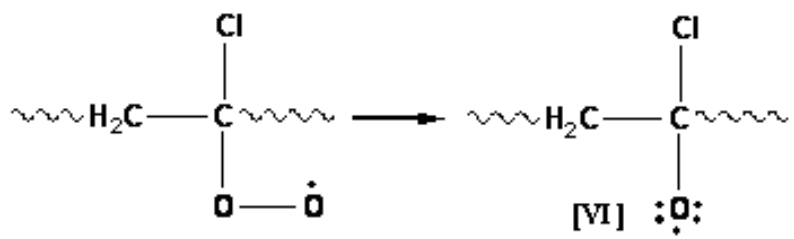

The most usual reaction of alkoxy radicals [VI] is the hydrogen abstraction. The unstable $\alpha$-chloroalcohol formed by reaction of alkoxy radical with PVC will rapidly decompose into the corresponding ketone. 


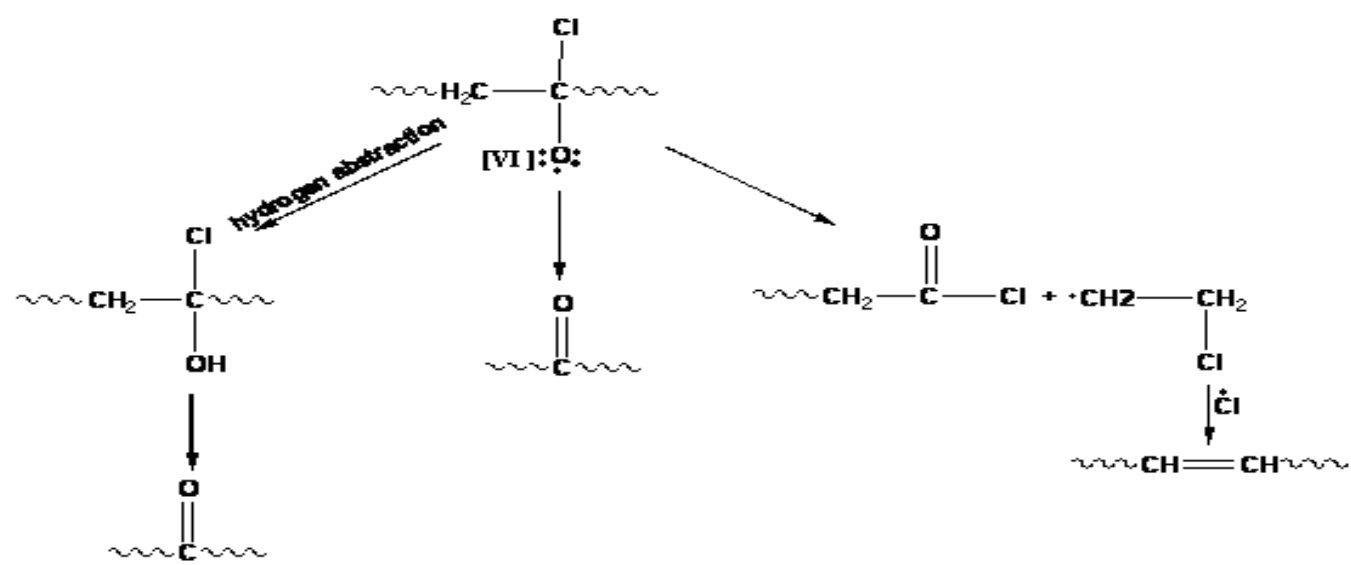

Tertiary alkoxy radicals are also proved to be stabilized by $\beta$-scission which may involve either $(\mathrm{C}-\mathrm{Cl})$ bond cleavage to form ketone or/and (C-C) bond cleavage to form polyene. The irradiation of PVC films with light of wavelength, $\lambda=$ $313 \mathrm{~nm}$ lead to a clear change in their FTIR spectrum, as shown in Figure (1). Appearance of bands at $1772 \mathrm{~cm}^{-1}$ and $1722 \mathrm{~cm}^{-1}$ respectively,

attributed to the formation of carbonyl group, the first is related to chloro ketone with the second one is due to aliphatic ketone, together with formation of a band at $1604 \mathrm{~cm}^{-1}$ related to polyene group. The hydroxyl band appeared at 3500 $\mathrm{cm}^{-1}$ is realated to alcohol functions (Andrady \& Searle 1989). The absorption of the polyene, carbonyl and hydroxyl groups are used to follow the extend of polymer degradation during irradiation. This absorption was calculated as carbonyl index (Ico), polyene index $\left(\mathrm{I}_{\mathrm{PO}}\right)$ and hydroxyl index $\left(\mathrm{I}_{\mathrm{OH}}\right)$. Therefore, one should expect that the growth of carbonyl index is a measure to the extent of degradation. As seen from Figure (2) that the modified polymers PAA, PSS, PNN, PSA and PNA show lower growth rate of carbonyl index with irradiation time with respect to unmodified PVC film (control). these modiefied polymers might be considered as photostabilized with respect to the PVC polymer. The good photostabilizer show a longer induction period. Therefore, from Figure (3), the PAA is the most active photostabilizer, followed by PSS, PNN, PSA and then PNA which is less active.As it was mentioned before polyene compounds are produced during photodegradation of PVC. Therefore, polyene index ( $\mathrm{I}_{\mathrm{PO}}$ ) was monitored with irradiation time. The same trend obtaind as carbonyl index. Hydroxyl functions are produced during photodegradation of PVC. Therefore, hydroxyl index $\left(\mathrm{I}_{\mathrm{OH}}\right)$ was monitored with irradiation time for unmodified PVC and modified PVC (PAA,PSS,PNN,PSA and PNA) polymers. From Figure (4) the PAA, PSS, PNN, PSA and PNA show lower growth rate of hydroxyl index with irradiation time with respect to PVC film without modification (control).

\subsubsection{Variation of PVC molecular weight during photolysis}

An analysis of the relative change in viscosity average molecular weight $(\overline{\mathrm{M}} \mathrm{v})$, Figure (5) shows the plot of $(\overline{\mathrm{M}} \mathrm{v})$ versus

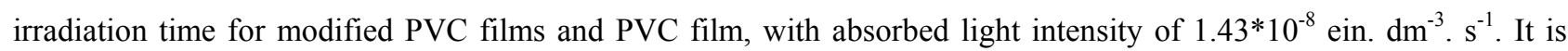
worth mentioning that traces of the films with additives are not soluble in THF indicating that cross-linking or branching in the PVC chain does occur during the course of photolysis. The plots indicate a rapid decrease in ( $\overline{\mathrm{M}} \mathrm{v})$ initially then it slows down, suggesting that the initial rapid drop in $(\overline{\mathrm{M}} \mathrm{v})$ is due to the main chain scission at various locations that distributed along the polymer chain. The photodegradation becomes slower and bond scission may be random. If the scission of bond is random, the rate of decrease in ( $\overline{\mathrm{M}} \mathrm{v})$ should be proportional to the square of the viscosity - average molecular weight at that irradiation time. Therefore, in order to clarify the type of bond scission the rate in the decrease of $(\overline{\mathrm{M}} v)$ with time, the value of $\left(\frac{\mathrm{d} \overline{\mathrm{M}}_{\mathrm{v}}}{\mathrm{dt}}\right)$ was calculated using the relation (8).

$$
\frac{d \bar{M}_{r}}{d t}=\frac{\bar{M}_{v, o}-\bar{M}_{v, t}}{t}
$$

Where $\overline{\mathrm{M}}_{\mathrm{v}, \mathrm{o}}$ and $\overline{\mathrm{M}}_{\mathrm{v}, \mathrm{t}}$ are viscosity average molecular weight at (zero) and (t) irradiation time respectively.

The plots Figure (6), shows $\frac{d \bar{M}_{v}}{d t}$ against $\left(\bar{M}_{v}\right)^{2}$, which were found to be not linear. The plots show that the weak bond links is randomly distributed along the polymer chains. For randomly distributed weak bond links, which break rapidly in the initial stages of photodegradation, the degree of deterioration $\alpha$ is given as: 


$$
\alpha=\frac{\mathrm{m}}{\overline{\mathrm{M}_{0}}}
$$

Where $\mathrm{m}$ and $\mathrm{Mv}_{0}$ are the molecular weights of irradiation time, respectively. The plot of $\alpha$ as a function of irradiation time is shown in Figure (7). The curves indicate that the degradation is taking place by the random breaking of one type of bond. The values of $\alpha$ of the irradiated samples are higher without presence of additives and lower in presence of additives compared to the corresponding values of the additive free PVC. In the initial stages of photodegradation of PVC, the values of $\alpha$ increases rapidly with time, which indicates a random breaking of bonds in the polymer chain. For more support of this view, the number average chain scission (average number cut per single chain) (S) was calculated using the relation (10):

$$
S=\frac{\overline{\mathrm{M}}_{\mathrm{v}, 0}}{\overline{\mathrm{M}}_{\mathrm{v}, \mathrm{t}}}-1
$$

Where $\overline{\mathrm{M}}_{\mathrm{v}, \mathrm{o}}$ and $\overline{\mathrm{M}}_{\mathrm{v}, \mathrm{t}}$ are viscosity average molecular weight at (zero) and (t) irradiation time respectively. The plot of $\mathrm{S}$ versus time is shown in Figure (8). The curve indicates an increase in the degree of branching such as might arise from cross-linking occurrence. It is observed that, insoluble material was formed during irradiation, an extra evidence to the idea that cross-linking dose occur. The plot of $1 / \mathrm{Pt}$ versus irradiation time is adopted to characterize degradation reaction of polymer as shown in Figure (9). The curve indicates that increase in the inverse of number average degree of polymerization with irradiation time

\subsection{Suggested mechanisms of photostabilization of PVC by modifaction}

Through the overall results obtained, the efficiency of modified polymers PVC films can be arranged according to the change in the carbonyl, polyene and hydroxyl Indexes as a reference for comparison as shown in Figure (2), (3) and (4).

$$
\text { PAA }>\text { PSS }>\text { PNN }>\text { PSA }>\text { PNA }
$$

1-The reaction between $\mathrm{PVC}$ and hetrocyclic units reduce the number of $\mathrm{HCl}$ in this polymer which led to decrese the probability of labraition $\mathrm{Cl}$ from PVC chain. (Scheme 2).

2-These polymers also function as radical scavengers through energy transfer and by forming unreactive charge transfer complexes between the modified polymers and excited state of the chromophore (POO) and stabilize through resonating structures as shown in Scheme (3).

3- The benzothiazole and benzimidazole rings in these modified polymers plays a role in the mechanism of the stabilizer process by acting as UV absorber. The UV light absorption by these polymers containing these heterocylic units dissipates the UV energy to harmless heat energy Scheme (4). Further more, this ring play a role in resonating structures conjugation of radical in peroxide decomposer Scheme (3), which support these rings as photostabilizer. Another way of degradation reaction characterization is the measurements of the quantum yield of the chain scission $(\Phi c s)$. The quantum yield for chain scission was calculated for PVC films of modified polymers. The $\Phi c s$ values for these polymers are tabulated in Table (4). The $\Phi_{\mathrm{cs}}$ values for modified PVC films are less than that of unmdified PVC (control), which increase in the order:

PAA, PSS, PNN, PSA, PNA, and PVC

The explanation of low values of $\Phi_{\mathrm{cs}}$ is due to that, in large molecule of PVC the energy is absorbed at one site, and then the electronic excitation is distributed over many bonds so that the probability of a single bond breaking is small, or the absorbed energy is dissipated by non reactive processes. It is well established that the quantum yield $\left(\Phi_{\text {cs. }}\right)$ increases with increasing temperatures around the glass transition temperature, $(\mathrm{Tg})$ of the amorphous polymer, and around the melting temperature of crystalline polymers. In the study presented in this work, the photolysis of PVC film is carried out at a temperature $\left(25-40^{\circ} \mathrm{C}\right)$ well blow the glass transition temperature $\left(\mathrm{Tg}\right.$ of $\left.\mathrm{PVC}=80^{\circ} \mathrm{C}\right)$. Therefore, the $\Phi_{\mathrm{cs}}$ dependency on temperature is not expected to be observed.

\section{Conclusions}

We prepared five modified polymers by the covalent modification of commercial PVC with benzothiazole and benzimidazole binding units. The modified polymers differ in their susceptibility to photooxidative degradation from that unmodified PVC. The photostability effects of these heterocyclic moities was indicated on the basis of carbonyl, 
polyene and hydroxyl indexes. The results obtained demonstrates that all the modified polymers are good photostabilizer rather than unmodified PVC.

\section{References}

Aliwi S., Yousif E. and Otaiwi A. (2006). Synthesis and photochemical study of some metal complexes of poly(vinyl chloride)-2-mercapto-5-phenyl 1,3,4-oxadiazole Iraqi J. Polymers, 10(1): 53-64.

Andrady, A. \& Searle, N. (1989). Photodegradation of rigid PVC formulations. II. Spectral sensitivity to light-induced yellowing by polychromatic light. Journal of Applied Polymer Science, 37:2789-2802.

Andrady, A., Hamid, S., Hu, X. \& Torikai, A. (1998). Effects of Increased Solar Ultraviolet Radiation on Materials. Journal of Photochemistry and photobiology B-Biology 46: 96-103.

Gardette, J., Gaumet, S. \& J. L. Philippart, J. (1993). Influence of the experimental conditions on the photooxidation of poly(vinyl chloride). Journal of Applied Polymer Science, 48(11): 1885-1895.

Jellinek, H. (1978). Aspects of Degradation and Stabilization of polyolefines, Elsevier, Amsterdam.

Mark, J. (2007). Physical Properties of Polymers Handbook. Springer, New York.

Mori, F., Koyama, M. \& Oki, Y. (1977). Studies on photodegradation of poly(vinyl chloride) (part 1). Die Angewandte Makromolekulare Chemie, 64(1): 89-99.

Nakajima, N., Sadeghi, M. \& Kyu, T. (1990). Photodegradation of poly(methyl methacrylate) by monochromatic light: Quantum yield, effect of wavelengths, and light intensity. Journal of Applied Polymer Science, 41: 889 - 1363.

Pittmann C. (1980). Polymer Supported Reactions in Organic Synthesis, P. Hodge and D. C. Sherrington, Eds., Wiley, New York, Chap. 5.

Rabek, J., Ranby, B. (1975). Photodegradation, photo-oxidation and Photostabilization of Polymers, John Wiley, New York.

Shyichuk, A. \& White, J. (2000). Analysis of chain-scission and crosslinking rates in the photo-oxidation of polystyrene. Journal of Applied Polymer Science 77(13): 3015-3023.

Yousif E., Hameed S. and Bakir E. (2007). Synthesis and photochemical study of of poly(vinyl chloride) 1,3,4-oxadiazole and 1,3,4-thiadiazole. Journal of Al-Nahrain University, 10(1): 7-12.

Yousif, E., Farina, Y., Kasar, K., Graisa, A. \& Ayid. K. (2009). Complexes of 2-Thioacetic Acid Benzothiazole with Some Metal Ions. American J. of Applied Sciences, 6(4): 605-608.

Zhang, H., Zhang, J., Chen, J., min Hao, X., Shanyuan Wang, S., Xinxing Fenga, X. \& Guo, Y. (2006). Effects of solar UV irradiation on the tensile properties and structure of PPTA fiber. Polymer Degradation and Stability, 91(11): 2761-2767.

Table 1. The Sofftening point of the prepared polymers

\begin{tabular}{lcc}
\hline Polymer & Color & $\begin{array}{c}\text { Sofftening } \\
\text { point }\left({ }^{0} \mathrm{C}\right)\end{array}$ \\
\hline PAA & White & $92-95$ \\
PSS & Yellow & $103-106$ \\
PNN & Brown & $161-167$ \\
PSA & Brown & $141-146$ \\
PNA & Brown & $130-138$ \\
PVC & Colorless & $200-205$ \\
\hline
\end{tabular}


Table 2. Characteristic absorption bands of polymers

\begin{tabular}{|c|c|c|}
\hline Polymer Symbol & IR Spectral Data $\left(\mathrm{cm}^{-1}\right)$ & Assignment \\
\hline PAA & $\begin{array}{l}3274 \\
3058 \\
2923 \\
1635 \\
1531 \\
1438 \\
1303 \\
763 \\
628\end{array}$ & $\begin{array}{l}\mathrm{N}-\mathrm{H} \text { stretching } \\
\mathrm{C}-\mathrm{H} \text { stretching of benzene ring } \\
\mathrm{C}-\mathrm{H} \text { stretching of }-\mathrm{CH}_{2}^{-} \\
\mathrm{C}=\mathrm{N} \text { stretching of thiazole ring } \\
\mathrm{C}=\mathrm{C} \text { stretching of end of } \mathrm{PVC} \text { chain } \\
\mathrm{C}-\mathrm{H} \text { bending of }-\mathrm{CH}_{2^{-}} \\
\mathrm{C}-\mathrm{H} \text { bending of }-\mathrm{CH}_{3} \\
\mathrm{C}-\mathrm{H} \text { bending of ortho disubstituted benzene } \\
\text { ring } \\
\mathrm{C}-\mathrm{Cl} \text { stretching }\end{array}$ \\
\hline PSS & $\begin{array}{l}3025 \\
2900 \\
1630 \\
1589 \\
1434 \\
1350 \\
655\end{array}$ & $\begin{array}{l}\mathrm{C}-\mathrm{H} \text { stretching of benzene ring } \\
\mathrm{C}-\mathrm{H} \text { stretching of }-\mathrm{CH}_{2-}^{-} \\
\mathrm{C}=\mathrm{N} \text { stretching of thiazole ring } \\
\mathrm{C}=\mathrm{C} \text { stretching of end of } \mathrm{PVC} \text { chain } \\
\mathrm{C}-\mathrm{H} \text { bending of }-\mathrm{CH}_{2-} \\
\mathrm{C}-\mathrm{H} \text { bending of }-\mathrm{CH}_{3} \\
\mathrm{C}-\mathrm{Cl} \text { stretching }\end{array}$ \\
\hline PNN & $\begin{array}{l}3375 \\
3070 \\
2931 \\
1646 \\
1569 \\
1458 \\
1319 \\
732 \\
621\end{array}$ & $\begin{array}{l}\mathrm{N}-\mathrm{H} \text { streching } \\
\mathrm{C}-\mathrm{H} \text { streching of benzen ring } \\
\mathrm{C}-\mathrm{H} \text { stretching of }-\mathrm{CH}_{2}- \\
\mathrm{C}=\mathrm{N} \text { stretching (being broad) } \\
\mathrm{C}=\mathrm{C} \text { stretching of end of } \mathrm{PVC} \text { chain } \\
\mathrm{C}-\mathrm{H} \text { bending of }-\mathrm{CH}_{2^{-}} \\
\mathrm{C}-\mathrm{H} \text { bending of }-\mathrm{CH}_{3} \\
\mathrm{C}-\mathrm{H} \text { bending of ortho disubstituted benzene } \\
\text { ring } \\
\mathrm{C}-\mathrm{Cl} \text { stretching }\end{array}$ \\
\hline PSA & $\begin{array}{c}3200 \\
3078 \\
2896 \\
1616 \\
1531 \\
748 \\
651\end{array}$ & $\begin{array}{l}\mathrm{N}-\mathrm{H} \text { stretching (being broad) } \\
\mathrm{C}-\mathrm{H} \text { stretching of benzene ring } \\
\mathrm{C}-\mathrm{H} \text { stretching of }-\mathrm{CH}_{2}- \\
\mathrm{C}=\mathrm{N} \text { stretching (being broad) } \\
\mathrm{C}=\mathrm{C} \text { stretching of end of } \mathrm{PVC} \text { chain } \\
\mathrm{C}-\mathrm{H} \text { bending of ortho disubstituted benzene } \\
\text { ring } \\
\mathrm{C}-\mathrm{Cl} \text { stretching }\end{array}$ \\
\hline PNA & $\begin{array}{l}3270 \\
2931 \\
1643 \\
1539 \\
1450 \\
1328 \\
750 \\
628\end{array}$ & $\begin{array}{l}\mathrm{C}-\mathrm{H} \text { stretching of benzene ring } \\
\mathrm{C}-\mathrm{H} \text { stretching of }-\mathrm{CH}_{2}^{-} \\
\mathrm{C}=\mathrm{N} \text { stretching of imidizole ring } \\
\mathrm{C}=\mathrm{C} \text { stretching of end of } \mathrm{PVC} \text { chain } \\
\mathrm{C}-\mathrm{H} \text { bending of }-\mathrm{CH}_{2-}^{-} \\
\mathrm{C}-\mathrm{H} \text { bending of }-\mathrm{CH}_{3} \\
\mathrm{C}-\mathrm{H} \text { bending of ortho disubstituted benzene } \\
\text { ring } \\
\mathrm{C}-\mathrm{Cl} \text { stretching } \\
\text { N-Hstretching(being broad) }\end{array}$ \\
\hline $\mathrm{PVC}$ & $\begin{array}{c}2970,2910,2860 \\
1429 \\
615.2\end{array}$ & $\begin{array}{l}\mathrm{C}-\mathrm{H} \text { streching of }-\mathrm{CH}_{2} \text { and }-\mathrm{CH}- \\
\mathrm{C}-\mathrm{H} \text { bending of }-\mathrm{CH}_{2-}^{-} \\
\mathrm{C}-\mathrm{Cl} \text { stretching }\end{array}$ \\
\hline
\end{tabular}


Table 3. Electronic spectra of polymers in THF solvent

\begin{tabular}{|c|c|}
\hline Polymer & Absorption Bands(nm) \\
\hline PAA & $234,262,293$ \\
\hline PSS & 230,324 \\
\hline PNN & $224,276,281$ \\
\hline PSA & 226,265 \\
\hline PNA & $234,249,270$ \\
\hline PVC & 219,254 \\
\hline
\end{tabular}

Table 4. Quantum yield $\left(\Phi_{\mathrm{cs}}\right)$ for the chain scission for PVC and modified PVC films $(30 \mu \mathrm{m})$ thickness after 250 hrs. irradiation time

\begin{tabular}{cc}
\hline Additive $(0.5 \% \mathrm{wt})$ & quantum yield of main chain scission $\left(\Phi_{\mathrm{cs}}\right)$ \\
\hline PAA & $1.11 \mathrm{E}-07$ \\
PSS & $1.36 \mathrm{E}-07$ \\
PNN & $1.39 \mathrm{E}-07$ \\
PSA & $1.59 \mathrm{E}-07$ \\
PNA & $2.82 \mathrm{E}-07$ \\
PVC & $5.12 \mathrm{E}-05$ \\
\hline
\end{tabular}

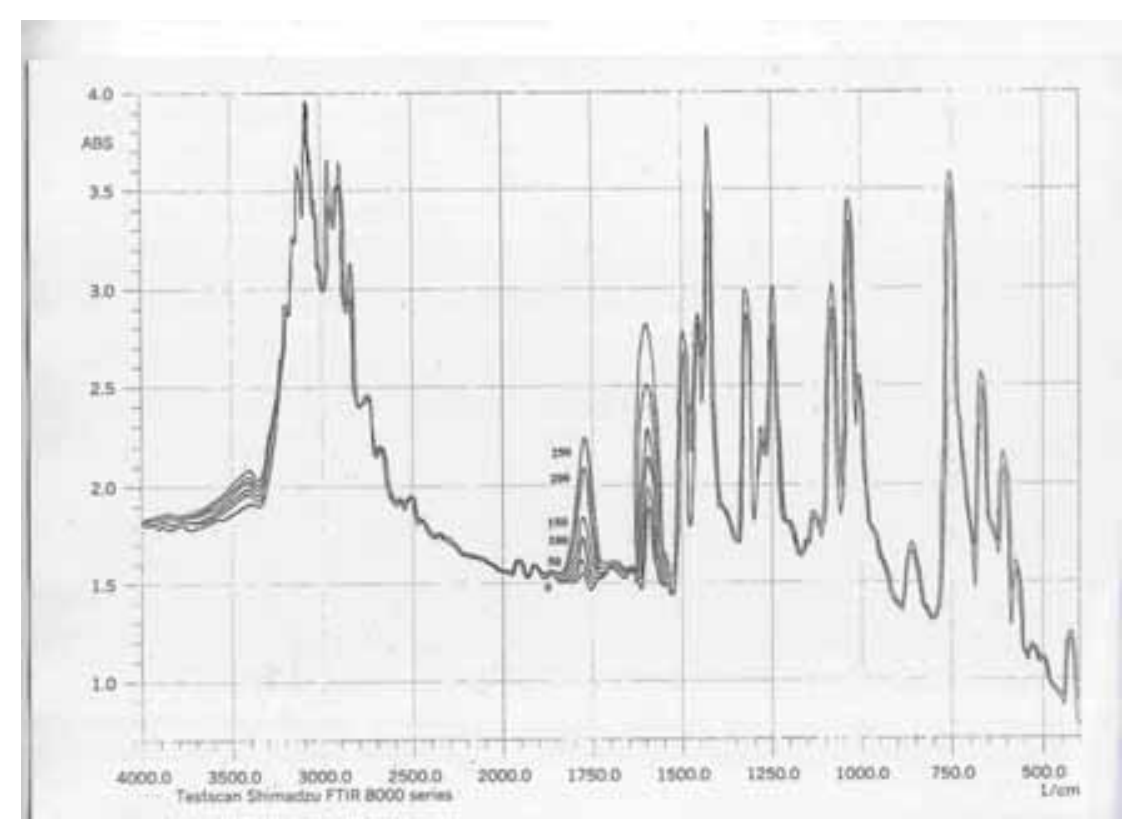

Figure 1. Change in IR spectrum of PVC film $(30 \mu \mathrm{m})$ in the presence of $\mathrm{Cd}(\mathrm{L})_{2}$ complex. (Numbers n spectra are irradiation time in hours) 


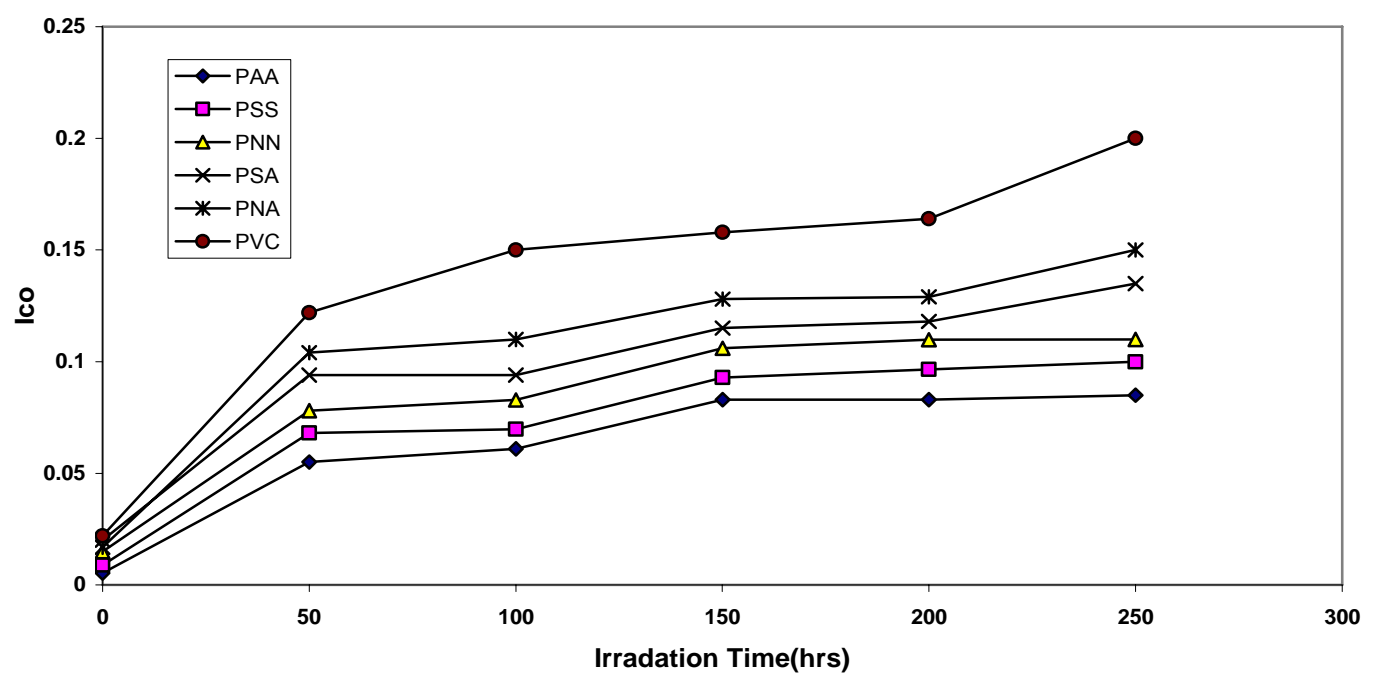

Figure 2. The relationship between the carbonyl index and irradiation time for PVC and modified PVC films $(30 \mu \mathrm{m})$ thickness

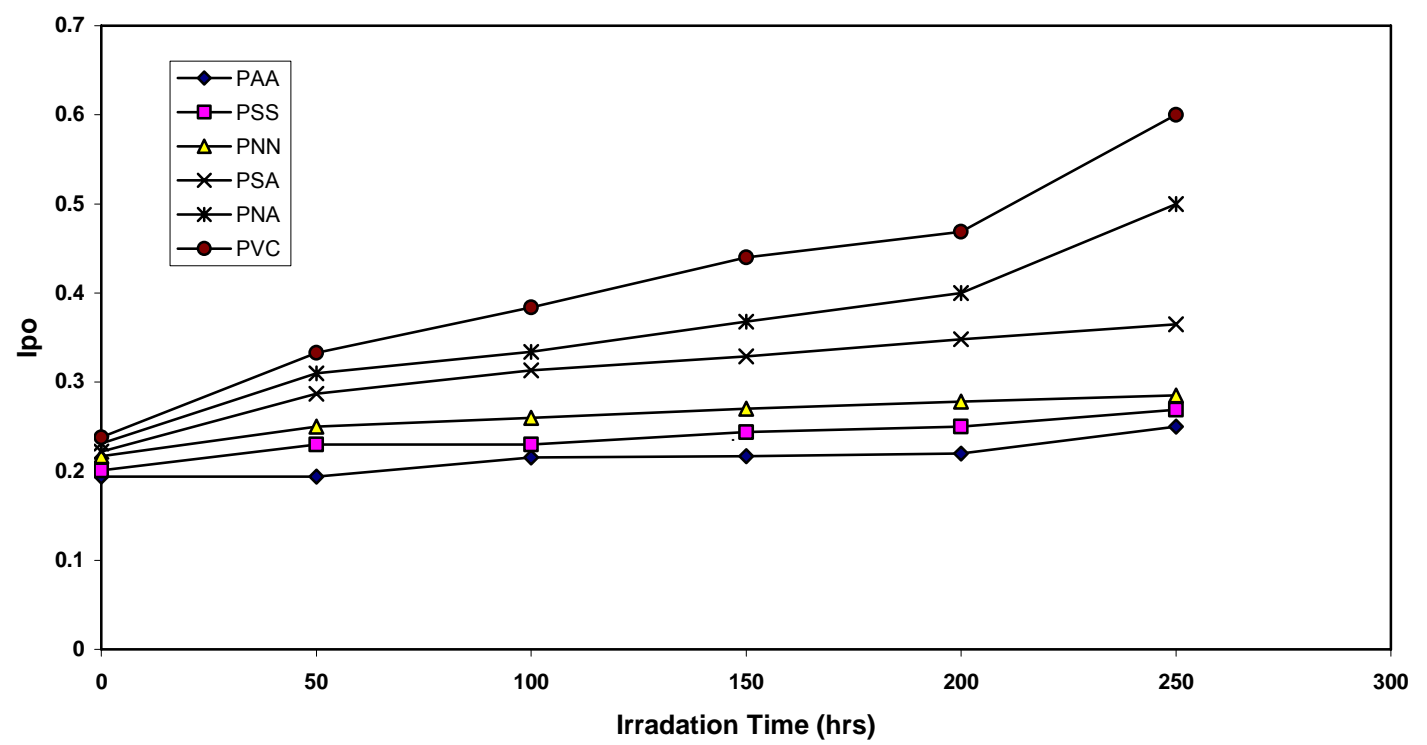

Figure 3. The relationship between the polyene index and irradiation time for PVC and modified PVC films $(30 \mu \mathrm{m})$ thickness 


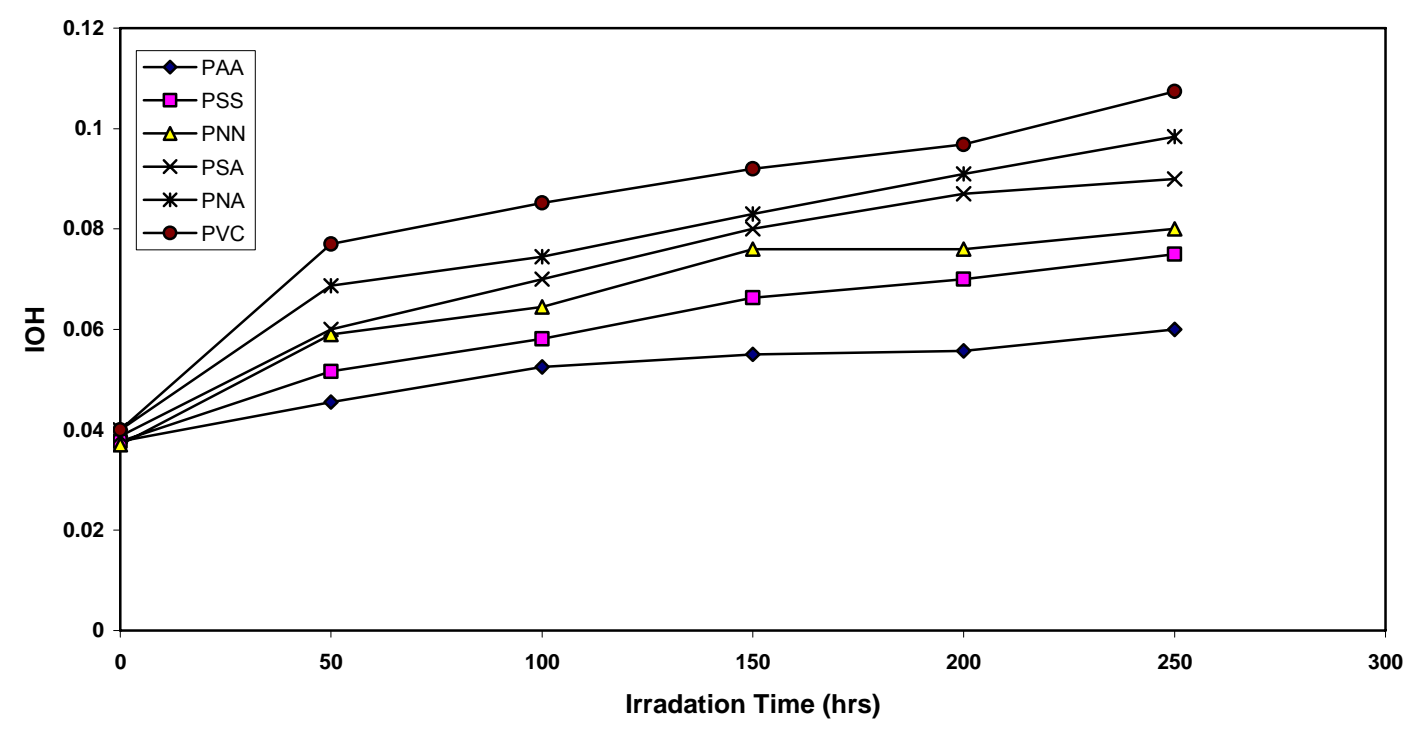

Figure 4. The relationship between the hydroxyl index and irradiation time for PVC and modified PVC films $(30 \mu \mathrm{m})$ thickness

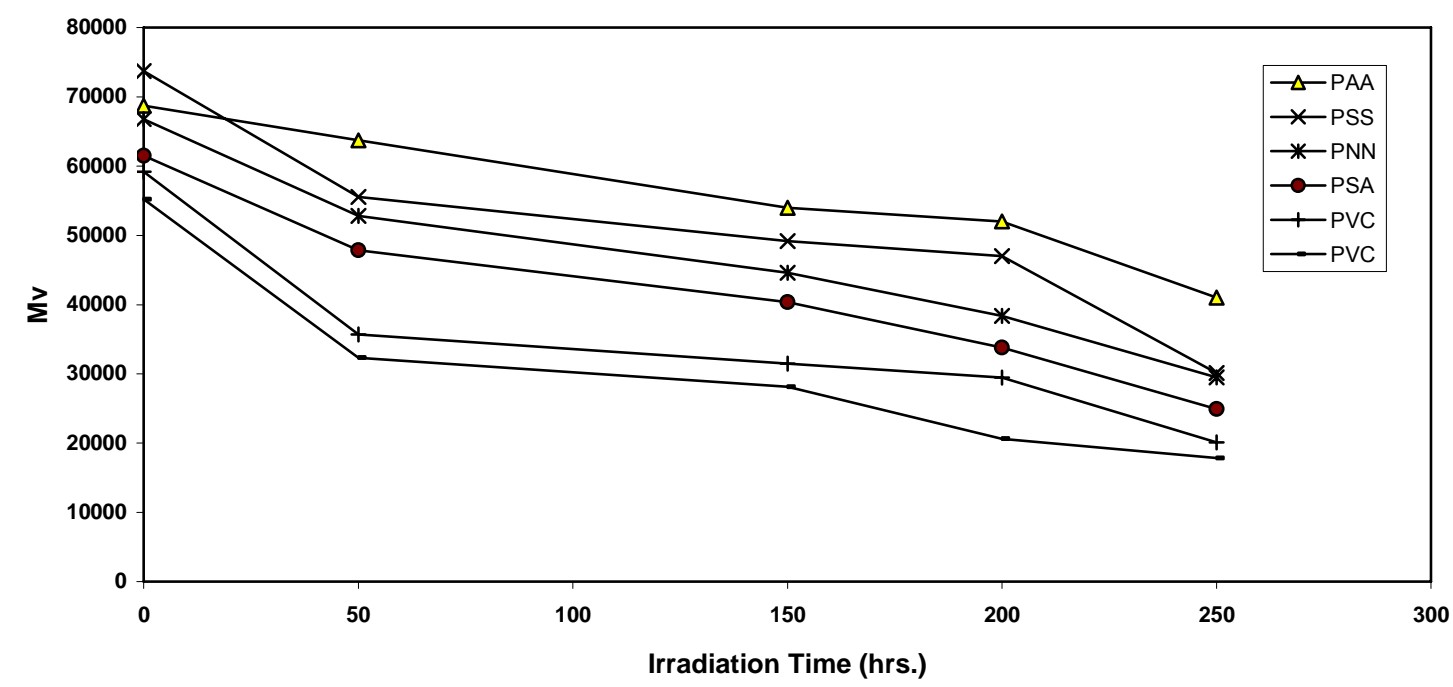

Figure 5. Changes in the viscosity average molecular weight $(\overline{\mathrm{M}} \mathrm{v})$ during irradiation of PVC films $(30 \mu \mathrm{m})(\mathrm{control})$ and modified PVC 


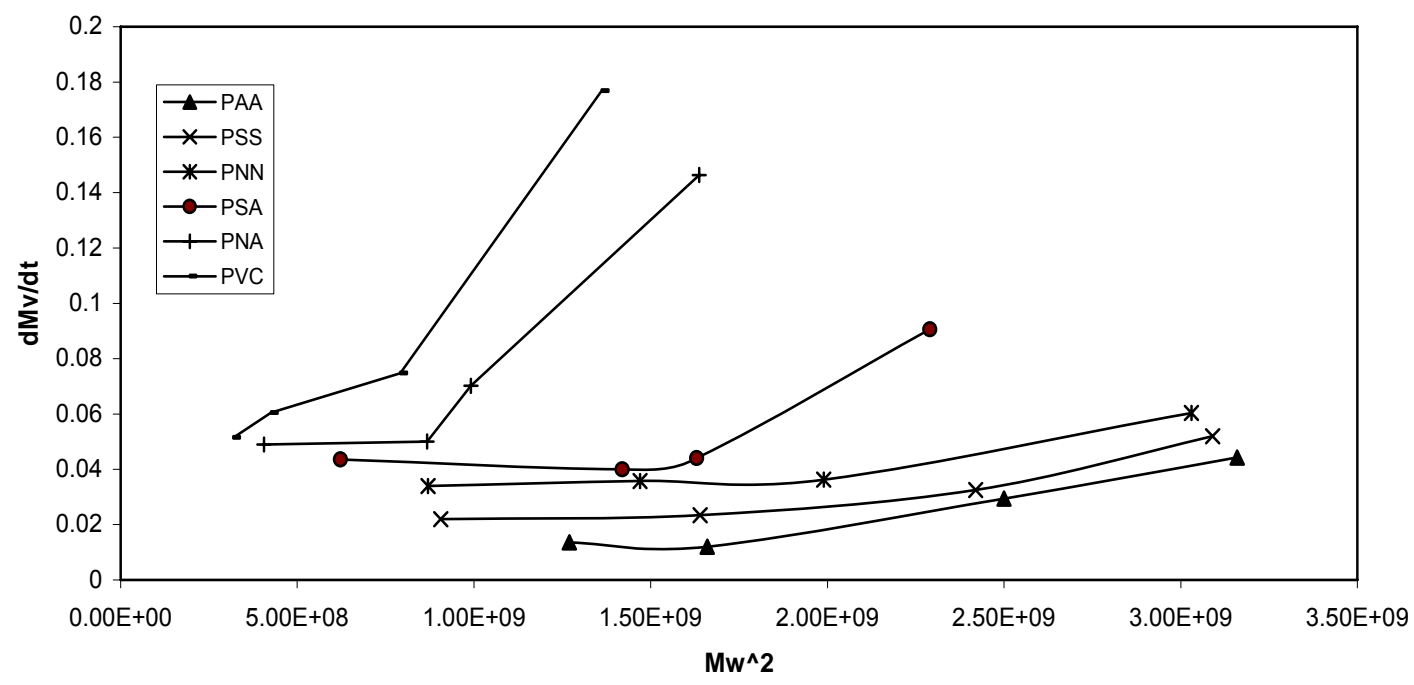

Figure 6. Rate variation of molecular weight change $(\mathrm{d} \overline{\mathrm{M}} \mathrm{v} / \mathrm{dt})$ during irradiation of PVC films $(30 \mu \mathrm{m})$ (control) and modified PVC films

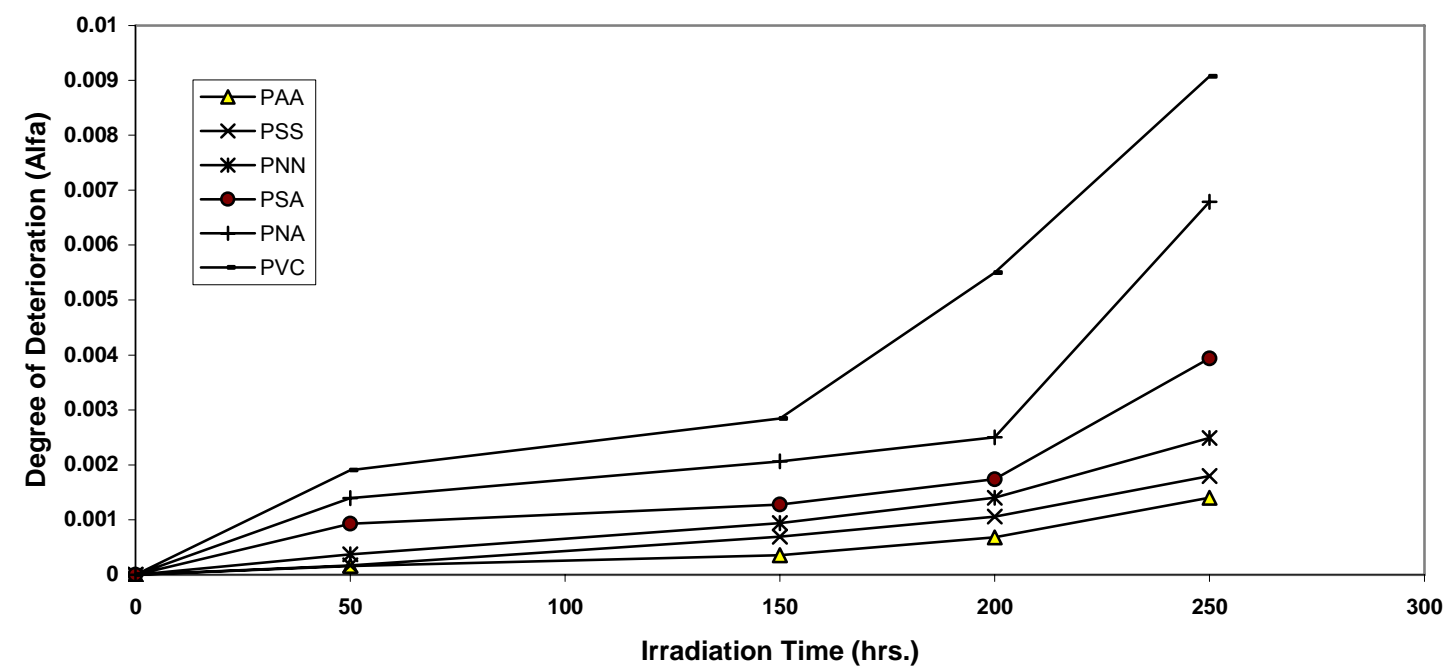

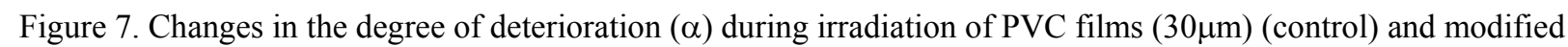
PVC films 


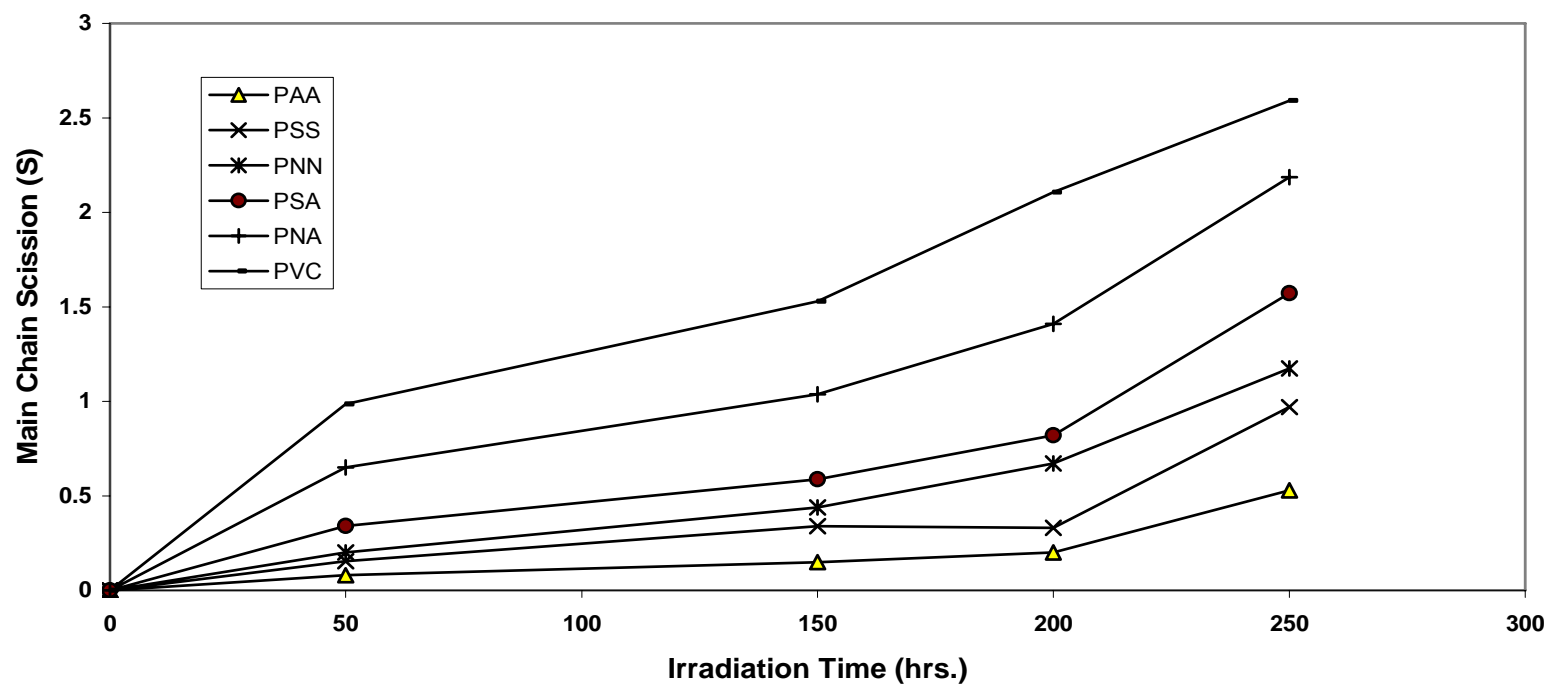

Figure 8. Changes in the number average chains during irradiation of PVC films $(30 \mu \mathrm{m})$ (control) and modified PVC films

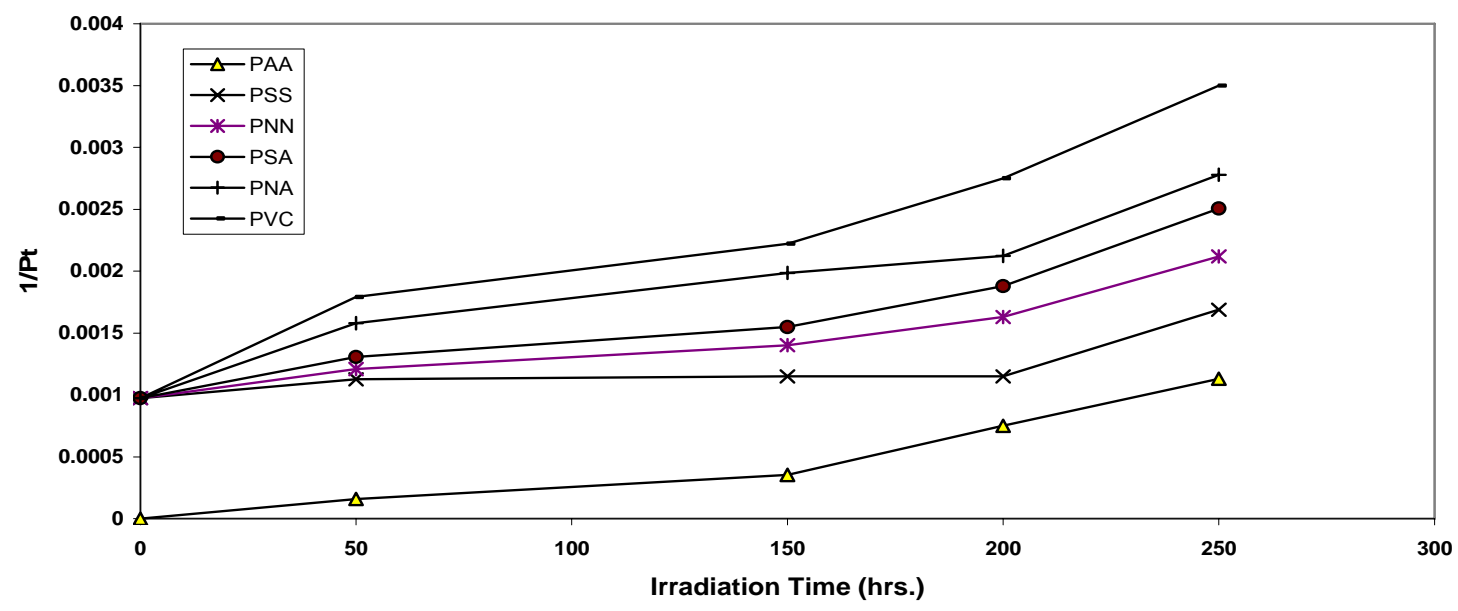

Figure 9. Changes in thereciprocal of number average of polymerization $(1 / \mathrm{Pt})$ during $313 \mathrm{~nm}$ during irradiation of PVC films $(30 \mu \mathrm{m})$ (control) and modified PVC films 


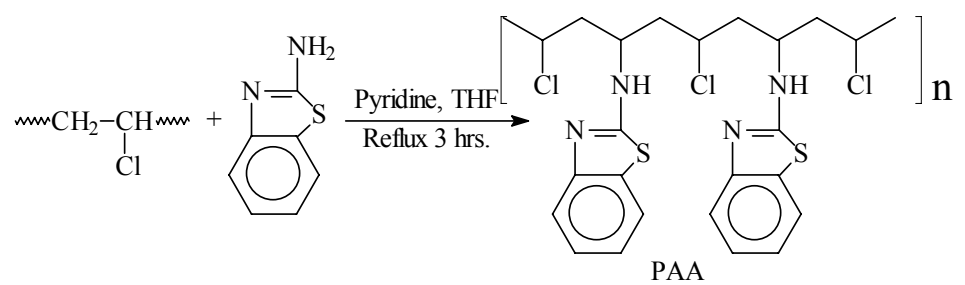

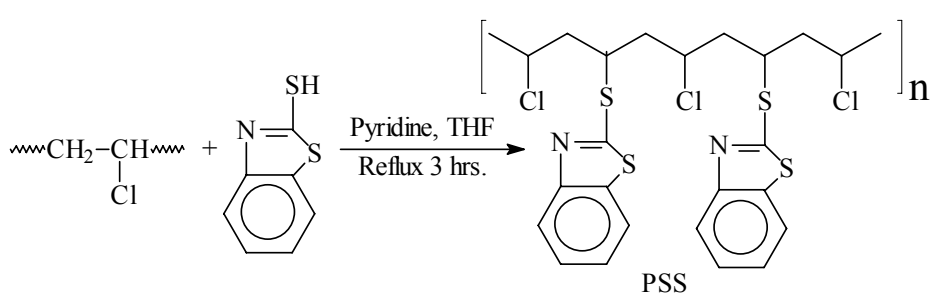

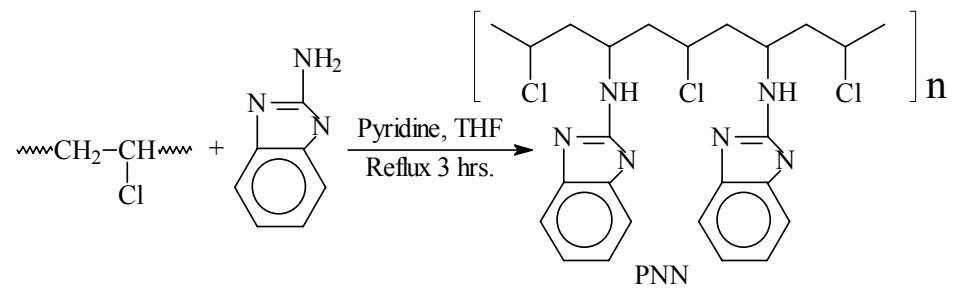

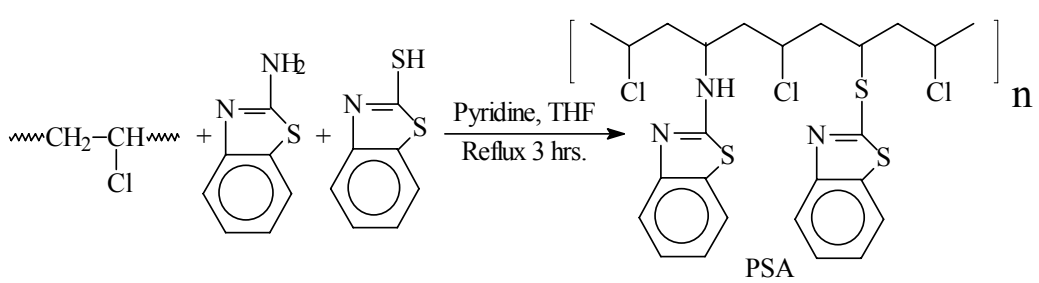<smiles>CC[C@H](Cl)[C@@H]1N=C(N)[CH-]c2ccccc21</smiles>

Scheme 1. Chemical reaction of preparation of polymers 


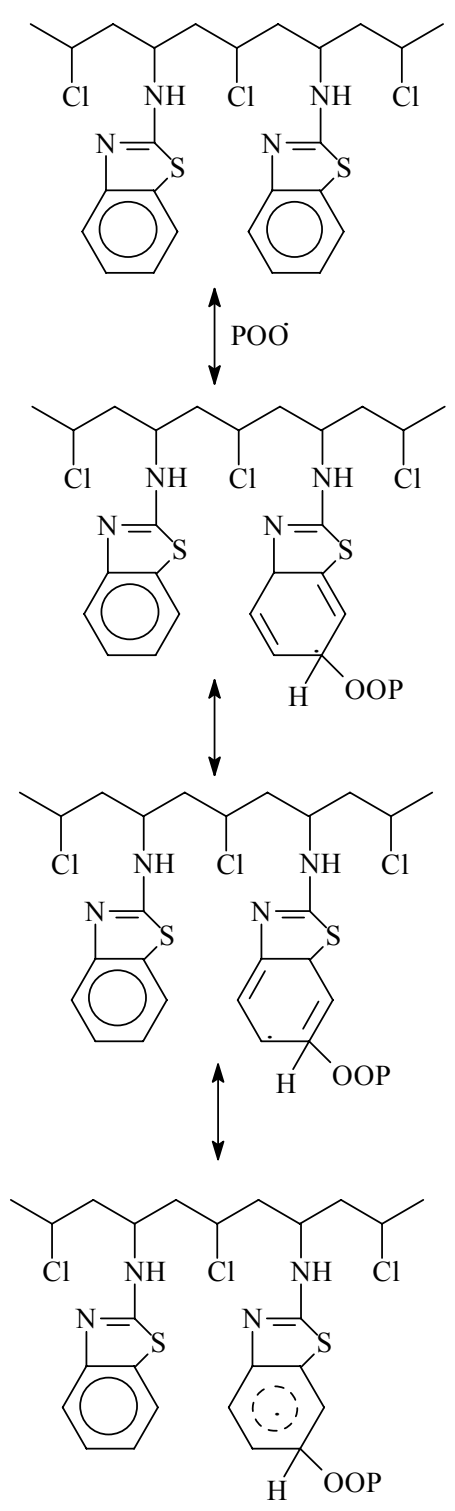

Scheme 2. Suggested mechanism of photostabilization of PAA as radical scavengers through energy transfer and forming unreactive charge transfer and stabilize through resonating structure.
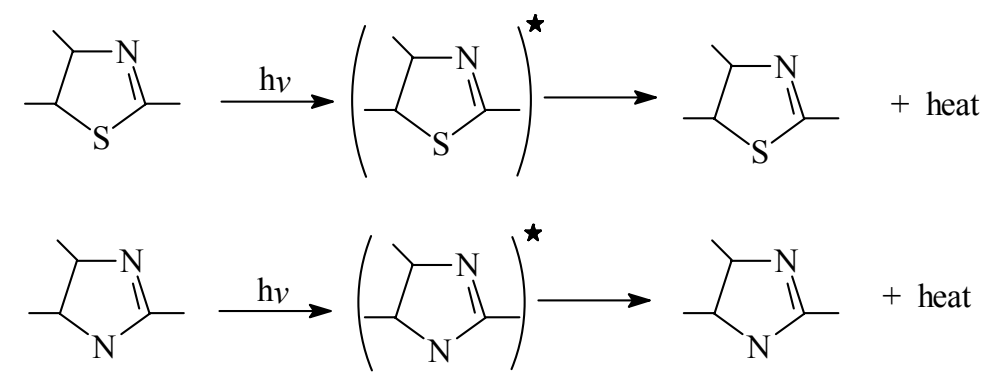

Scheme 3. Suggested mechanism of photostabilization of modified polymers as UV absorber. 